\title{
ОСОБЕННОСТИ РЕАЛИЗАЦИИ ФИНАНСОВОГО ОБЕСПЕЧЕНИЯ И ФИНАНСОВОГО РЕГУЛИРОВАНИЯ КАК СТРУКТУРНЫХ ПОДСИСТЕМ ФИНАНСОВОГО МЕХАНИЗМА В СИСТЕМЕ РЕГУЛИРОВАНИЯ ПРОСТРАНСТВЕННОГО РАЗВИТИЯ ГОСУДАРСТВА
}

\section{FEATURES OF THE IMPLEMENTATION OF FINANCIAL SUPPORT AND FINANCIAL REGULATION AS STRUCTURAL SUBSYSTEMS CONTAINED IN THE SYSTEM OF THE FINANCIAL MECHANISM FOR REGULATING THE SPATIAL DEVELOPMENT OF THE STATE}

A. Gurovich I. Chistov

Summary. The authors present for the study the currently existing subsystems of financial support and financial regulation that make up the system of the financial mechanism for regulating the spatial development of the state. The types of financial support systems are described in detail. The problems of financial regulation carried out in the field of distributive relations are indicated, as well as the methods that are included in the content of the financial regulation system are highlighted. The presented features, on the basis of which the guiding action of the financial mechanism is implemented, have an active influence in regulating the spatial development of Russia and its subjects.

Keywords: spatial development; financial mechanism; financial security; financial regulation; bankroll; credit; guaranty; budget.
Гурович Андрей Михайлович

К.э.н., заместитель министра, Министерство Российской Федерации по делам гражданской обороны, чрезвычайным ситуациям и ликвидации последствий стихийных бедствий, г. Москва a_m_gurovich@mail.ru

Чистов Игорь Вадимович Заслуженный деятель науки Российской Федерации, д.э.н., профессор, Военный университет Министерства обороны Российской Федерации,

2. Москва

ivchistov@mail.ru

Аннотация. Авторами рассматриваются существующие подсистемы финансового механизма в системе регулирования пространственного развития государства, каковыми являются финансовое обеспечение и финансовое регулирование. Детально охарактеризованы типы систем финансового обеспечения. Затронуты аспекты финансового регулирования, реализующегося в области распределительных отношений, с выделением способов, входящих в содержание системы финансового регулирования. Указанные особенности, обуславливающие действие финансового механизма, активно влияют на регулирование пространственного развития Российской Федерации и регионов.

Ключевые слова: пространственное развитие; финансовый механизм; финансовое обеспечение; финансовое регулирование; денежные средства; кредит; обязательства; бюджет.

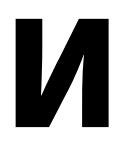
звестно, что такие методы регулирования, как финансовое обеспечение и финансовое регулирование, являясь структурными подсистемами финансового механизма регулирования пространственного развития государства, оказывают существенное влияние по основным направлениям развития Российской Федерации и регионов. Определение важности использования данных методов обусловлено принятой в государстве финансовой политикой.
Используя указанные методы, можно заметить их непосредственное взаимодействие друг с другом. Организованная в тех либо иных условиях система финансового обеспечения нуждается в эффективно функционирующих инструментах финансового регулирования.

Исходя из практического опыта, прослеживается реализация финансового обеспечения путем образования систем следующих типов: 
- самостоятельно формирующих источники обеспечения денежными средствами;

- получающих денежные средства на условиях их возвратности;

- вкладывающих денежные средства с целью получения дохода;

- предоставляющих денежные средства путем их направления одним бюджетом другому бюджету[4].

Подробно рассмотрим указанные типы систем финансового обеспечения. Начнем с систем, самостоятельно формирующих источники обеспечения денежными средствами. Системы, обеспечивающие развитие всех сфер деятельности путем формирования денежных средств собственными источниками, относятся к элементарным типам финансового обеспечения. Пожалуй логично, что не имея собственных свободных средств, мы не можем участвовать в любых финансово-экономических отношениях в любой области, будь то производство, строительство, сфера услуг и т.д. В том числе, без наличия денежных средств отсутствует возможность гарантировать эффективное развитие указанных областей.

Следует обратить внимание на существующие в настоящее время направления, которые предпринимаются для образования денежных средств, а также их рациональное использование. В связи с этим осуществляются определенные мероприятия аналитического и прогнозного характера. На их основе делаются расчетные операции, в результате которых оценивается необходимость и целевое использование собственных денежных средств.

Хотелось бы предупредить, что формирование денежных средств за счет собственных источников не должно приводить к суждению о замкнутости экономики и отсутствии внешних связей, так как в любых условиях имеется возможность привлечения кредитных денежных средств, возврат которых следует осуществить собственными средствами. Поэтому, формирование денежных средств собственными источниками нужно выделять, как основополагающий элемент финансового обеспечения.

Можно подчеркнуть, что при формировании денежных средств, используя собственные источники, поддержка материального благосостояния обеспечивается с помощью заемных денежных средств. Данное обстоятельство принуждает разграничивать собственные и кредитные средства [5].

Учитывая статистические сведения, полученные из зарубежных и отечественных источников, стоит ука- зать, что средства, сформированные за счет собственных ресурсов, характеризуются целевым назначением, выраженном в возмещении своих постоянных расходов на предельно возможных показателях. Средства, полученные из других источников, образуются на условиях возвратности за определенную плату в виде процента.

Система финансового обеспечения, функционирующая за счет самостоятельного формирования денежных средств, имеет положительные и отрицательные черты. Одной из положительных черт данной системы является то, что эта система финансового обеспечения содействует оптимальному расходованию присутствующих средств путем увеличения их кругообращения. Отрицательной же чертой является ситуация, при которой денежные средства накапливаются, отсутствует динамика их обращения. Данное обстоятельство ведет к снижению уровня развития.

Следующей разновидностью систем финансового обеспечения являются системы, получающие денежные средства на условиях их возвратности. Рассмотрим сущность и содержание данных систем. Функционирование рассматриваемых систем состоит в пользовании кредитными средствами в пределах определенного срока. По сравнению с предыдущими системами, характеризуемыми в качестве основополагающих частей финансового обеспечения, системы, пользующиеся кредитными средствами, определены как наиболее существенные и важные элементы, включенные в систему финансового обеспечения [7]. Средства, полученные за счет заемных операций, имеют возвратный характер, ограничены сроком использования, наделены обязательством по оплате процентов за пользование предоставленным кредитом.

Заметим, что пользование кредитными средствами позволяет сберегать собственные средства, которые можно направить на определенные цели или инвестировать для получения дополнительных средств. Вступая в заемные отношения, мы принимаем установленные требования, обуславливающие обеспечение исполнения обязательств, предоставление кредитных средств на определенный срок. Кроме того, оцениваем выгодные условия привлечения заемных средств и эффективность их использования.

Обратимся теперь к системам, вкладывающим денежные средства с целью получения дохода. Вкладывая средства в финансовые активы на продолжительный срок, создается возможность постоянного наблюдения за их динамикой, анализом происходящих с ними изменений, а также возможность осуществлять оценку разумности и целесообразности вложения средств в те либо иные активы [6]. 
Существуют разные способы вложения денежных средств. Так, имеются вложения на длительный срок, как правило, в реальные активы, в большинстве случаев в основные фонды. В том числе, вложения в ценные бумаги. Такие вложения обеспечивают привлечение дохода от недвижимости и другого имущества [8].

Система финансового обеспечения, предоставляющая денежные средства путем их направления одним бюджетом другому бюджету, тоже имеет актуальное значение. Это обусловлено тем, что бюджетные средства представляют собой источники, с помощью которых исполняются бюджетные обязательства в субъектах Российской Федерации. Направления использования бюджетных средств различны. Среди огромного спектра этих направлений можно выделить следующие целевые назначения бюджетных средств:

- осуществление работ, предоставление услуг, обоснованных государственными нуждами [3];

- обеспечение социальной сферы;

- увеличение за счет средств бюджета стоимости государственного (муниципального) имущества [1];

- предоставление денежных средств юридическим и физическим лицам в рамках предпринимательской деятельности;

- предоставление целевых (субсидии, субвенции) и нецелевых (дотации) межбюджетных трансфертов;

- предоставление платежей, взносов, безвозмездных перечислений участникам международных отношений;

- обеспечение долговых обязательств, образованных в государстве за счет заемных средств.

Однако, кроме рассмотренных типов систем финансового обеспечения, существуют и другие составляющие элементы, образующие обеспечение за счет определенных форм сосредоточения денежных средств. Например, обеспечение программ, имеющих государственное значение, осуществляется путем взимания налогов и сборов по установленным сферам деятельности.

Прежде чем подытожить наши суждения о структурных подсистемах финансового механизма в системе регулирования пространственного развития государства, каковыми являются финансовое обеспечение и финансовое регулирование, остановимся непосредственно на подсистеме финансовое регулирование. По нашему мнению, финансовое регулирование, являясь частью финансового механизма, строится с опорой на нормативно-правовую базу и реализуется в области распределительных отношений в государстве и регионах, а также на предприятиях, организациях и в учреждениgx.

Основываясь на опыте, накопленном в сфере распределительных отношений, можно констатировать наличие двух способов данных отношений:

- сальдовый, относящийся к бюджетному регулированию;

- нормативный, включающий использование методов бюджетного нормирования и налогового регулирования [2].

Указанными способами установлено, каким образом происходит образование доходов и порядок обеспечения финансовыми ресурсами. Сальдовый и нормативный способы структурно входят в содержание системы финансового регулирования.

Несомненно, применение того или иного способа распределительных отношений играет соответствующую роль в подсистеме финансового регулирования. Тем не менее, не стоит рассуждать об их сравнении. Важно то, какие элементы эти способы содержат.

Обратим внимание на составляющие элементы сальдового способа распределительных отношений. Представляет интерес то, что в данном методе решающее значение отдается обобщенному элементу, в котором необходимо сконцентрировать мотивирующие действия, осуществляемые в практической деятельности. При отсутствии указанного нами обстоятельства, следует усомниться в эффективности применяемого способа распределительных отношений, а также в выполнении цели финансового регулирования.

Важным мероприятием при применении нормативного способа распределительных отношений является определение рациональной пропорции между порядком, установленным в руководящих документах, и целевом использовании денежных средств.

Таким образом, рассмотрев подсистемы финансового механизма в системе регулирования пространственного развития государства, необходимо учитывать:

- применяемые на государственном уровне системы финансового обеспечения;

- обеспечение за счет определенных форм сосредоточение денежных средств;

- распределительные отношения, включающие сальдовый и нормативный способы регулирования;

- наличие других методов регулирования, определяющих действие финансового механизма в системе регулирования пространственного развития государства. 


\section{ЛИТЕРАТУРА}

1. Бюджетный кодекс Российской Федерации от 31 июля 1998 г. № 145-ФЗ // СЗ РФ. 1998. № 31. Ст. 3823.

2. Герасимова Л.Н. Теория бухгалтерского учета. - Ростов-на-Дону. 2010. - 350 с.

3. Гусев В.В. Бюджетные ассигнования на закупку товаров, работ, услуг для государственных (муниципальных) нужд // Современное общество и праB0. 一 2015.— № 3 (20). - C. 84-87.

4. Закутнев С.Е. Совершенствование бюджетной политики в сфере государственной поддержки реального сектора экономики / С.Е. Закутнев, А.С. Закутнева // Вопросы контроля хозяйственной деятельности и финансового аудита, национальной безопасности, системного анализа и управления: сборник материалов V Всероссийской научно-практической конференции. - 2020. - C. 70-73.

5. амбердиева С.С. Макроэкономические показатели страны и их антикризисное регулирование / С.С. Камбердиева, М.Ю. Мирзабекова // Наука и образование: прорывные инновационные исследования. Сборник статей Международной научно-практической конференции. - 2016. - С. 56-61.

6. Малова Т.А. Индикаторы инновационного развития российского нефтегазового сектора в условиях глобальной конкуренции // Экономика. Налоги. Право.— 2014. — № 2.—C. 72-78.

7. Семенкова Е.В. Актуальные проблемы привлечения инвестиций на фондовом рынке // Налоги и финансы. — 2015. — № 1 (25). — С. 14-22.

8. Федосов В.А. Проблема суверенных долгов в мировой экономике / В.А. Федосов, А.А. Молдован // Финансы и кредит. - 2013. C. 32-38. 